TRANSPORT FINDINGS

\title{
The Economics of Findings
}

\author{
Lewis Lehe $^{1}$, David Levinson ${ }^{2}$ (D) $\theta$ \\ ${ }^{1}$ Civil and Environmental Engineering, University of Illinois-Urbana-Champaign (IL), ${ }^{2}$ Civil Engineering, University of Sydney \\ Keywords: open access, publishing, academic, journal \\ https://doi.org/10.32866/001c.19105
}

Findings

This paper considers the monetary and time costs of producing Findings

(formerly Transport Findings). After enumerating the journal's expenses, we find the marginal monetary cost of an article is, on average, about $\$ 65$, and that the journal incurs $\$ 1966$ in fixed costs per year. Also, using data from a survey of Findings' reviewers and estimate of reviewers' value of time, we also calculate the time costs of operating findings. Most reviewers agree that compensating them for producing timely reviews would be an effective incentive.

\section{Questions}

Findings is an open-access, short-form research journal established in 2018 (as Transport Findings), with articles at about 1000 words. You are reading it now. As of the end of 2020 it has published 85 articles, as shown in Figure 1. As open-access publication has grown significantly over the past two decades $(\mathrm{Gu}$ and Blackmore 2016), and we expect will continue to increase, understanding the economics of journal publication will have value to others considering launching or converting existing journals, and we expect this case study to contribute to a more general conversation. We also hope short-form journals to become a useful antidote to the increasing length of journal articles in some more established journals (e.g. Bloem 2018), and a return to the roots of scientific publication.

This article asks the questions:

- What does it cost to operate Findings?

- What does it cost to produce an article?

- What are the possibilities for compensating reviewers?

\section{Methodology}

The methodology comprises two elements. The first is documenting the revenues and expenditures of Findings. The second aims to consider the unmonetized costs of producing Findings, which we estimate through a survey sent to 97 Findings reviewers (of which 27 replied) and an estimate of wages. Table 1 provides information about who responded to the survey. 


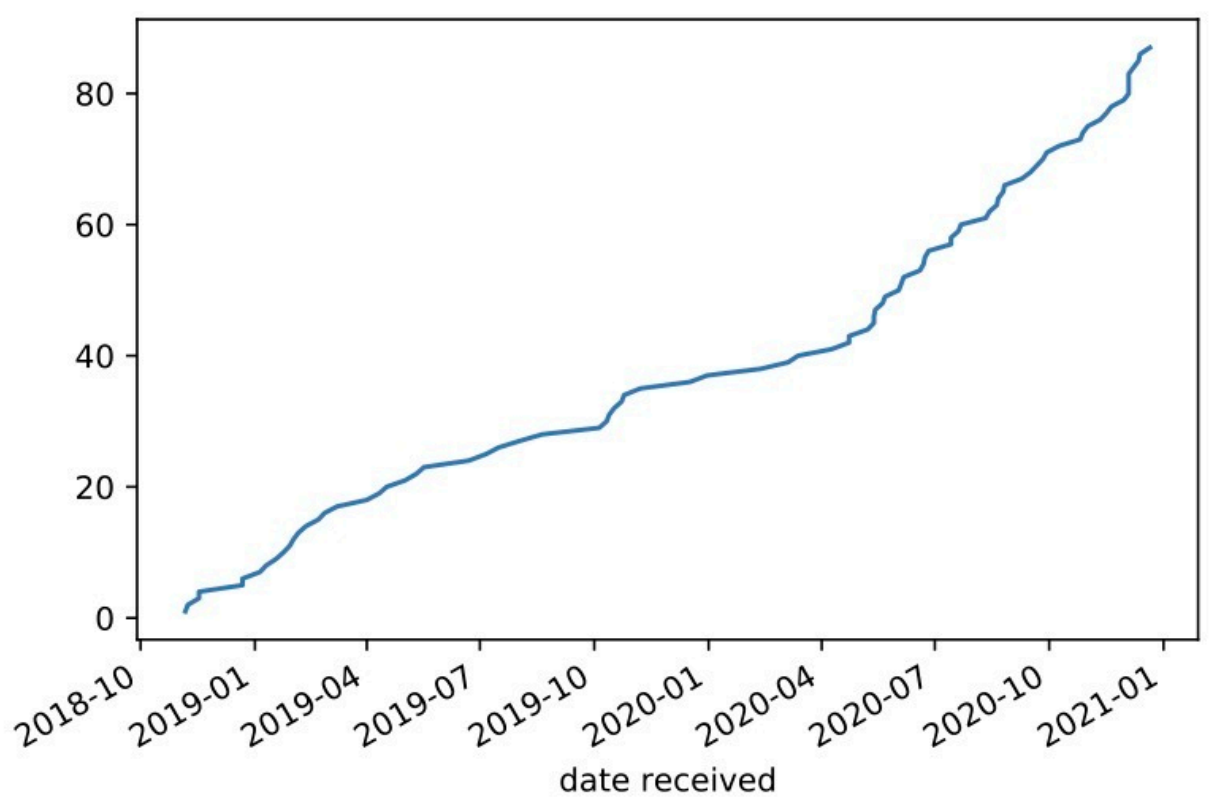

Figure 1: Cumulative acceptances by date of submission

Table 1: Description of Survey Respondents

\begin{tabular}{l|c}
\hline Category & Number \\
\hline Average Age & 42.4 \\
Male / Female & $18 / 9$ \\
Senior Prof. / Junior Prof. / Student / Other & $11 / 9 / 4 / 3$ \\
\hline Total respondents & 27 \\
\hline
\end{tabular}

Senior Prof. $=$ Full or Associate Professor or Reader.

Junior Prof. $=$ Assistant Professor or Lecturer.

\section{Findings}

\subsection{Monetary costs and revenues}

A summary of monetary expenses is shown in Table 2, where the first four items are devoted to expenses from Scholastica, an integrated, web-based service for publishing academic journals employed by the journal. The "Peer Review" add-on permits tracking reviews, decisions and communications within the standard Scholastica interface. Scholastica also provides typesetting services, which cost $\$ 5$ per 500 words and $\$ 7$ per table/figure; for this expense, Table 2 reports the average per-article cost of typesetting thus far. Beyond Scholastica, other expenses of online operation include:

- CrossRef: to register Digital Object Identifiers (DOIs), the standard for indexing and finding articles

- Hover: web domain registration 
Table 2: Monetary expenses of operating Findings.

\begin{tabular}{l|c|l|l}
\hline \multicolumn{2}{c}{ Amount (USD) } & \multicolumn{1}{l}{ Frequency } & \multicolumn{1}{l}{ Paid to } \\
\hline Publishing platform & 1,188 & annual & Scholastica \\
Peer review bundle & 250 & annual & Scholastica \\
Corporation annual report & 14 & annual & Illinois Secretary of State \\
Membership fee & 250 & annual & CrossRef \\
Archival service & 250 & annual & Portico \\
Domain registration & 14 & annual & Hover \\
\hline Submission fee & 10 & per article & Scholastica \\
Typesetting & 49.73 (average) & per article & Scholastica \\
Transaction fee & 4.95 & per article & Stripe \\
Incorporation & 50 & one-time & Illinois Secretary of State \\
\hline
\end{tabular}

The Transaction fee formula is $\$ 0.029+\$ 0.30$ per transaction, which comes out to $\$ 4.95$ per article, payable at the time of acceptance.

- Portico: an archival service that hosts permanent copies of the articles

Finally, there are the minor costs of incorporating Findings as a Not-For-Profit corporation with the State of Illinois, where the journal's Treasurer is based.

If we add together all per-article costs, we get a marginal or variable monetary cost of publication: $\$ 10$ (publication fee) $+\$ 4.95$ (transaction fee) $+\$ 49.73$ (average typesetting fee) $=\$ 64.68$ per article. Adding up the annual costs (and ignoring the trivial incorporation fee of $\$ 50$ ) gives an annual fixed cost of running the journal equal to $\$ 1966$. Thus, we get an annual monetary cost function $\left(c_{m}(n)\right)$ :

$$
c_{m}(n)=\$ 1966+\$ 64.68 n,
$$

where $n$ is the number of articles published.

In 2019 all articles went through an additional copyediting service (at a cost similar to typesetting), but this service has been stopped in 2020, with little noticeable effect on article readability, and with a reduction in article tracking overhead and publication time.

Each published article incurs one $\$ 50$ submission fee (paid at the time of submission) and one $\$ 100$ publication (typesetting and copyediting) fee. In the 2019 and 2020 there were initial seed donations of funds from The University of Sydney's TransportLab and McGill University's TRAM program (estimated at $\$ 3702$ (USD) in total) to help capitalize the journal to pay the initial fixed costs for the first two years, but have gone to approximately $\$ 0$ as of 2021 as the journal is now self-sustaining, and so are not included in this analysis. The revenue per published article is $\$ 150$, so each article contributes $\$ 150-\$ 64.68=\$ 85.32$ toward fixed costs. Thus, since $\$ 1966 / \$ 85.32 \approx \$ 23$ , the journal needs to publish 23 articles per year to "break even" in a monetary sense. 


\begin{tabular}{lcc}
\hline Statistic & Value & Units \\
\hline Time spent per first-round review (Findings) & 80 & $\mathrm{~min} / \mathrm{article}$ \\
Time spent per revise-and-resubmit (Findings) & 26.6 & $\mathrm{~min} / \mathrm{article}$ \\
Time spent per first-round review (other journals) & 200.9 & $\mathrm{~min} / \mathrm{article}$ \\
Time spent per revise-and-resubmit (other journals) & 106.2 & $\mathrm{~min} / \mathrm{article}$ \\
Completed reviews per year all journals & 20.8 & articles \\
Declined reviews per year for all journals & 19.1 & articles \\
\hline
\end{tabular}

\subsection{Time costs}

According to a database collected by the Chronicle of Higher Education, the average academic-year salary salary of engineering professors (all ranks) at 4-year public universities in the United States is \$94,730 (Chronicle of Higher Education n.d.). We chose this class of professor, because at this time a plurality of reviewers are academics in engineering departments of public research institutions. If the academic year contains about $52 \cdot 9 / 12=39$ weeks, and each week has 40 hours of work (roughly balancing holidays, lower nominal hours per week in some countries and organizations, and real work exceeding the budgeted time for most actual academics), the typical hourly wage comes to $\$ 94,730 /(40 \cdot 39)=\$ 60.72$ per hour.

The Editor estimates he spends about one hour per article (reading papers, finding reviewers, making decisions, document preparing, responding to queries, etc.). The Treasurer spends about ten minutes per article, and the Social Media Manager spends about five minutes. So the total administrative time spent per article is $1.25 \mathrm{hrs}$. In addition, the Treasurer spends about 15 hours per year on tax, banking and incorporation and the Editor spends eight hours per year on general management unrelated to the publication of a particular article. As already stated, reviewers spend 106.6 minutes per article reviewing. Multiplying these figures by our $\$ 60.72 /$ hour figure gives time costs. These non-monetary costs appear in Table 4. Adding time costs to the fixed and marginal monetary costs calculated earlier yields a "full" average cost function $\left(c_{f}(n)\right)$ :

$$
c_{f}(n)=\$ 3362.66+\$ 248.46 n .
$$

Note the total time spent reviewing for a Findings article is about equal to the time spent reviewing a revision at other journals, which is explained by the observations that a Findings article is significantly shorter than typical articles in other journals within the same fields.

\subsection{Possibilities for compensation}

In addition, we asked: "Would you be more likely to review papers within 48 hours if you were paid to review?" Among the $55.6 \%$ of respondents who answered "Yes" and 25.9\% who answered "Maybe," the mean amount of 


\begin{tabular}{lccc}
\hline Item & Minutes & Monetary equivalent (USD) & Frequency \\
\hline Editor managing review/publication & 60 & $\$ 60.72$ & per article \\
Social media manager tweeting article & 5 & $\$ 5.06$ & per article \\
Treasurer issuing invoices/accounting & 10 & $\$ 10.12$ & per article \\
Reviewer time & 106.6 & $\$ 107.88$ & per article \\
Treasurer doing taxes/compliance/banking & 900 & $\$ 910.87$ & annual \\
Editor managing journal & 720 & $\$ 485.79$ & annual \\
\hline
\end{tabular}

money needed to review within 48 hours was $\$ 60.70$. To review within one week, the mean amount of money required was $\$ 38.10$. The share answering "no" was $18.5 \%$. This required compensation is less than our estimate based on hourly wage, indicating reviewers probably benefit from reviewing as well (and of course often conduct reviews during compensated work hours already).

While the economic model of the journal does not yet permit reviewer or editor compensation, we anticipate some form compensation or credit system will become mainstream in future years.

In closing, we would note that the full cost of producing an article in Findings is significantly less than the open access charges of some more famous journals (Markin 2017; Grossmann and Brembs, [version 1; peer review: awaiting peer review]). Recognizing that reviewer, and often editor, labor for those journals is uncompensated, we are left to wonder where those extra revenues go. 


\section{REFERENCES}

Bloem, J. 2018. “Are Economics Papers Too Long? Jeffrey R. Bloem .” Blog. July 2018.

Chronicle of Higher Education. n.d. "Faculty Salaries 2018-2019 Academic Year.” Accessed December 12, 2020. https://data.chronicle.com/category/sector/1/faculty-salaries/.

Grossmann, Alexander, and Björn Brembs. [Version 1; peer review: awaiting peer review]. "Current Market Rates for Scholarly Publishing Services.” F1000Research 10 (20). https://doi.org/10.12688/ f1000research.27468.1.

Gu, Xin, and Karen L. Blackmore. 2016. "Recent Trends in Academic Journal Growth.” Scientometrics 108 (2): 693-716. https://doi.org/10.1007/s11192-016-1985-3.

Markin, P. 2017. “How Much Do Top Publishers Charge for Open Access?” Open Science Resources, April 2017. https://openscience.com/how-much-do-top-publishers-charge-for-openaccess/. 